\title{
IMPORTANCE OF First-YeAR ENGINEERING DESIGN Projects to SELF-EFFiCACY: Do FirST-YEAR STUdENTS FEEL LIKE ENGINEERS?
}

\author{
Jon-Michael J. Booth and Thomas E. Doyle \\ McMaster University \\ boothjj@mcmaster.ca and tdoyle@ieee.org
}

\begin{abstract}
Self-efficacy, a belief that one can achieve a certain level of attainment, is important to student retention in engineering and technology fields. Developing ways to increase self-efficacy should be a primary concern for engineering programs. Several key tasks will be investigated including (a) the importance of design projects to self-efficacy in first-year engineering, and (b) making first-year engineering students feel like engineers. A team-based "Cornerstone" design project was undertaken by first-year engineering students as part of a Design and Graphics course. Two groups of firstyear engineering students were surveyed, (1) students who had completed the course and design project in first term, and (2) students who were enrolled in the second term offering of the same course, before completing the design project. The survey focused on Bandura's four identified sources of self-efficacy: (a) Mastery experiences, (b) Vicarious experiences, (c) Social persuasions, and (d) Physiological states, as well as a fifth often added characteristic (e) Drive and motivation. Additionally, students were asked to quantify their agreement or disagreement to the statement "I feel like an Engineer." This paper will present the results between these two groups and will be of interest to faculty involved in freshmen design.
\end{abstract}

Keywords: engineering, self-efficacy, involvement, design, first-year, cornerstone, project

\section{INTRODUCTION}

Engineering design projects are an important learning tool for first-year university students who are taking their first big step into the world of engineering. These projects provide a structured approach to the design process, giving students a solid understanding of how to move from a mere concept to a working model of a system. These projects not only give students the knowledge and skills to produce such outcomes, but also give students confidence in their abilities to complete future projects.
Engineering 1C03 Design and Graphics is a first-year engineering course at McMaster University. The course consists of three weekly parallel components: 1) lecture on design background and theory, 2) tutorial focusing on hand-sketching, calculations, and design on paper, and 3) computer lab session where students get hands-on experience with solid modeling software (AutoDesk Inventor) and a physical modeling and system simulation application (MapleSim). The course concludes with a Cornerstone design project, where students must retrofit an existing product, design new elements (in our case, a simple gear train), solid model those elements, and create a real-time, working simulation in MapleSim.

The goals of the Cornerstone design project are to promote new ways of thinking about design, provide new tools for visualization and presenting those designs, and to increase self-efficacy and confidence to produce better designs in the future. The desire is to create an atmosphere of community, an appetite for self-motivated inquiry, and a sense of belonging to the Engineering profession.

\subsection{Motivation}

Often confused are the terms self-efficacy and selfconfidence which are closely related. Self-confidence is the more general term, indicating a belief in one's own abilities. Self-efficacy is more specific, in that it adds a desired level of attainment to those beliefs. The two can more easily be differentiated by comparing the confidence statement, "I am good with computers" to the efficacy statement, "I can use 3D modeling software to create a gear train." In the second statement, the specific goal of creating a gear train is the desired level of attainment.

Theory suggests that increasing self-efficacy will have a direct, positive effect on achievement $[1,2]$. That is to say, students who believe in their own abilities to achieve a goal will perform much greater than students who do not. The challenge to educators becomes how to increase self-efficacy in students such that the increase will 
positively affect their course and project performance, their grades, and ultimately their future in the profession.

As educators and course designers, we have the ability to modify the student curriculum to improve skills, increase participation, increase involvement and community interaction, and increase confidence in students' abilities to overcome any challenge. The first step toward increasing involvement and self-efficacy is to measure the current levels, so that we can make course and curriculum changes, and watch how those changes relate to the observed effects in self-efficacy and involvement.

\subsection{Literature Review}

Many studies have been conducted using self-efficacy as an indicator of performance or ability [3]. All of them link back to work by Bandura [4] within the context of Social Cognitive Theory, where he identifies four sources for efficacy beliefs: Mastery experiences, Vicarious experiences, Social persuasions, and Physiological states. Work by Hutchinson et al [5] identifies another commonly used source of self-efficacy as Drive and motivation that are not included in Bandura's original work. The Hutchinson paper also outlines the differences between self-confidence and self-efficacy, and was the basis for our decision to create a first-year engineering survey.

Since the authors' work is based on self-efficacy in first-year engineering students, the task was approached from the idea of what creates self-efficacy and confidence in one's own abilities, related to first-year engineering. Data was found [6,7] suggesting that self-efficacy in first-year engineering can be linked directly to the amount of exposure a student has to engineering and related courses prior to entering a university setting. HutchinsonGreen et al [7] concluded that high-school successes are the most influential basis for engineering confidence. Given that their work must begin at the university level, the authors turned their attention to studies that took place there.

A study conducted at Purdue University [8] found a noticeable correlation between self-efficacy and achievement in a course-related project, confirming Bandura's self-efficacy theory. Further, it found that students who offer support to other students in a team environment had overall higher self-efficacy scores. An online survey [9] given to first-year engineering students in a programming class suggests that students with a greater self-efficacy will expend a greater effort toward projects. Carberry et al [10] show a direct correlation between engineering self-efficacy and engineering attainment, with higher scores resulting from more experience in the engineering field.

Based upon a review of the literature and the application, the authors created a tool for measuring self- efficacy, based partly on the Generalized Self-efficacy scale [11], a widely-used tool for assessing self-efficacy in a number of disciplines, and Bandura's own suggestions [12] for creating a unique scale specifically for our own purposes.

\subsection{Problem Definition}

Self-efficacy is a timely topic, and as such has a lot of related research $[6,8,13]$. Links between self-efficacy and achievement are accepted, as higher self-efficacy tends to provide higher performance $[1,4,8,10]$. On the other hand, little research has been conclusive about the causes and contributing factors to self-efficacy. Surely, increasing self-confidence and self-efficacy is important, but how does one go about increasing self-efficacy?

The Authors propose to study the effects of the student Cornerstone design project on self-efficacy and a sense of belonging to the engineering community. This paper will focus on the differences between students who have not completed the design project and students who have completed the design project by offering survey results and data collected from students in each group.

\subsection{Solutions Considered}

This paper differentiates between two student populations: 1) students who had already taken the course and completed the design project, and 2) students who had not. Initially the study planned to offer two surveys; one to be delivered before the project, and a second to be delivered after the project. Given the length of the survey and the time required, the authors decided that each student should only be asked to complete one such survey.

In the initial plan, each term of students were to be surveyed once before the Cornerstone project completion, and once upon conclusion of the course. The results from each term of students were to be compared. Two problems arose with this methodology: 1) limited sample size, and 2) as many as four months may have passed between the first survey and the second. Many factors including time of year, exams, other courses, personal life, etc. could taint the results and potentially offer no solid conclusions regarding the design project.

To provide a more temporally consistent sample, a single survey for all first-year engineering students was given during the second term, which differentiated students who had completed the project from students who had not. The number of additional courses taken was minimized to one (a programming course that runs opposite terms to ENG 1C03) and the survey respondents were asked to consider the design project in every aspect of their answers. 


\subsection{Selected Methodologies}

A 22-question survey was created, consisting entirely of Likert-scale questions. Students were asked to rate agreement or disagreement on an eleven-point scale, from zero to ten for each of the questions. Bandura [12] suggests that the results will be more accurate if the scale is increased, so the authors chose an eleven-point scale to offer a clear center point for impartial responses. The survey was offered to 958 students in first-year engineering, and presented as an online survey which could be completed at any time within a one-month time span leading up to the conclusion of the design project for those students currently enrolled in ENG 1C03. Students who had completed the course and design project in the previous term were asked to follow the same timeline.

The questions were created from the five identified sources of self-efficacy, as well as from the widelyavailable Generalized Self-efficacy scale [11]. Four questions were used for Mastery experiences, three questions were used for Vicarious experiences, three were used for Social persuasions, two for Physiological states and one for Drive and motivation. An additional eight questions were derived from the Generalized Self-efficacy scale, but slightly reworded to include direct references to the design project. One additional question was added; "I feel like an Engineer."

\subsection{Significance of the Results}

This paper will explore the differences between groups of students who have completed the ENG 1C03 course (including the design project) and those who have not by exploring the responses to survey data collected. These differences will provide valuable insight for educators and course designers working with first-year engineering students who wish to increase self-efficacy in students, leading to a greater involvement, higher retention and increased performance in engineering courses.

\section{SURVEY RESPONSES}

The survey had 111 total valid respondents from the first-year engineering population. From this, 67 were currently enrolled in ENG $1 \mathrm{C} 03$ and actively working on the final design project at the time of the survey, hereafter known as the Pre-Project Group. The remaining 48 respondents were in their second term of engineering, having previously completed the design project in the first term, hereafter known as the Post-Project Group. Results from these two groups will be discussed relating to each of the self-efficacy question categories.

\subsection{Mastery Experiences}

Mastery experiences are the students' personal interpretations of their own performance specifically related to course work and skill. Sample questions which gauge these experiences are "Weekly lab and tutorial assignments prepared me for the design project" and "I have sufficient computer skills to conceptualize any design."

Respondents from the Pre-Project Group responded with a mean of 6.799 (on a 10 point scale) and with a standard deviation of 1.782 compared to students in the Post-Project Group who responded with a mean of 7.125 and with a standard deviation of 1.391. The statistical significance value was $\rho=0.292$.

\subsection{Vicarious Experiences}

When a respondent does not have direct experience with an item, often they relate their perceived success with that achieved by others. In the case of the design project survey, these Vicarious experiences include perceptions of team member contributions and accomplishments from previous terms. A sample question might be "Knowing a project has been successfully completed by others makes me believe I am capable of completing the same project."

Respondents from the Pre-Project Group had a mean of 7.970 with a standard deviation of 1.430 compared to the Post-Project Group with a mean of 7.965 and a standard deviation of 1.533 . The statistical significance value was $\rho=0.986$.

\subsection{Social Persuasions}

Social persuasions include the verbal judgments of peers, such as other (non-team member) students, professors or teaching assistants, as well as public forums where asking for help can be seen. Sample questions include "I often seek the advice of friends (non-team members) when completing a design project" or "Encouragement from my Prof or TA is important to my ability to complete any project."

Respondents from the Pre-Project Group had a mean of 6.075 with a standard deviation of 1.988 compared to the Post-Project Group with a mean of 6.236 and a standard deviation of 1.864 . The statistical significance value was $\rho=0.660$.

\subsection{Physiological States}

Interest, enjoyment and satisfaction with a course and its content are the foundations for Physiological states. If students enjoy the work they are doing, they should be more confident in their abilities to do it. Sample questions 
include "I would be more likely to succeed in a course project if I already had a good mark in the course."

Respondents from the Pre-Project Group had a mean of 6.687 with a standard deviation of 1.893 compared to the Post-Project Group with a mean of 6.635 and a standard deviation of 1.515. The statistical significance value was $\rho=0.877$.

\subsection{Drive and Motivation}

Although not specifically identified by Bandura, some believe that the desire to better oneself or the desire to achieve success itself should be an additional source of self-efficacy. For this reason, an additional question was added to the survey related to Drive and motivation. This question stated simply "I want to succeed, so I will succeed."

Respondents from the Pre-Project Group had a mean of 8.134 with a standard deviation of 2.044 compared to the Post-Project Group with a mean of 8.188 and a standard deviation of 1.709. The statistical significance value was $\rho=0.883$.

\subsection{Generalized Self-Efficacy}

An additional eight questions were added to the survey to increase the reliability of the data. These questions were derived from questions taken from the Generalized Self-Efficacy (GSE) scale. A sample question from the GSE, "I can remain calm when facing difficulties because I can rely on my coping abilities" was modified to "I am able to cope and remain calm when facing project difficulties."

Respondents from the Pre-Project Group had a mean of 7.323 with a standard deviation of 1.507 compared to the Post-Project Group with a mean of 7.263 and a standard deviation of 1.179. The statistical significance value was $\rho=0.819$.

\subsection{Total Average From All Categories}

For completeness, a total average score was calculated based on all 21 self-efficacy questions. Respondents from the Pre-Project Group had a mean of 7.115 with a standard deviation of 1.248 compared to the Post-Project Group with a mean of 7.175 and a standard deviation of 1.000. The statistical significance value was $\rho=0.785$.

\section{8 "I feel like an Engineer"}

Students were asked for a response to one additional question; "I feel like an Engineer." This question was included to get a general understanding as to whether or not first-year engineering students feel as though they are already a part of the engineering profession.
Respondents from the Pre-Project Group had a mean of 6.030 with a standard deviation of 2.995 compared to the Post-Project Group with a mean of 6.563 and a standard deviation of 2.475 . The statistical significance value was $\rho=0.315$.

\section{RESULTS AND DISCUSSION}

In terms of mean average, most of the numbers obtained as survey results are very close. Given the low number of respondents and the fixed values for response this makes sense. However, digging a little deeper into the response data causes some trends to emerge.

Figure 1 shows the mean average responses by category for each of the six categories of questions asked. It also includes an aggregate average self-efficacy score, and an average excluding the Generalized Self-efficacy scale data, which is somewhat non-specific. In this chart, the Pre-Project Group represents students who are currently enrolled in ENG 1C03 and who have not yet completed the design project. The Post-Project Group represents students who completed the course and design project in the previous term. Note that the scale of the graph has been modified to highlight the relevant data.

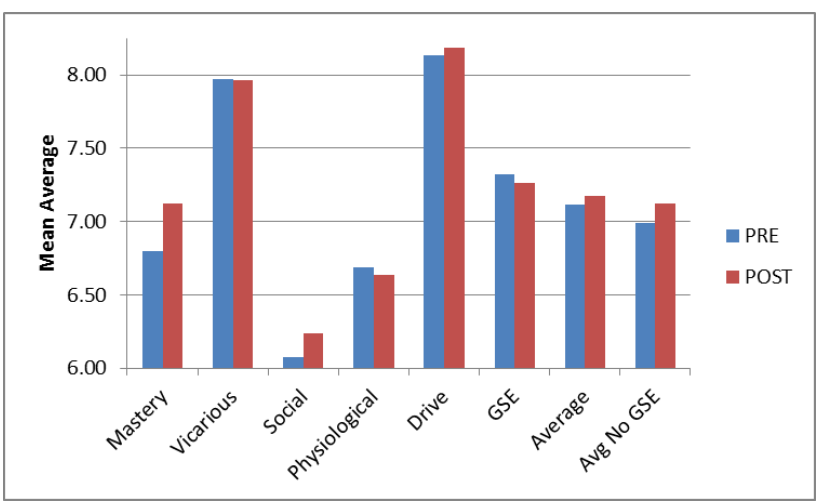

Figure 1: Self-efficacy by category

\subsection{Mastery Experiences}

Mastery experiences encompass course work undertaken by the student and how understanding of this material affects self-efficacy. The general belief is that self-efficacy increases with the level of student involvement, understanding and growing expertise in a particular field. Most studies find the biggest changes in this category and the data here provides no exception.

Efficacy scores are higher and deviation is lower for the Post-Project Group in this category. Further, $67.2 \%$ of the Pre-Project Group students answered with a score of 7 or higher compared to $74.0 \%$ of the Post-Project Group students. This difference between groups is further exaggerated when we look at students who answered 8 or higher, where the numbers become $40.7 \%$ for the PreProject Group and $49.0 \%$ for the Post-Project Group. 
The most noticeable difference was in the question "I am confident I can deal with any problems I encounter during a design project" where the Post-Project Group had a mean response of 7.500 and the Pre-Project Group had a mean of 6.642. Clearly the students who had completed the design project were more confident in their abilities to complete another.

\subsection{Vicarious Experiences}

Students use Vicarious experiences by way of seeking help from peers and team members and using those combined experiences to establish what their own personal experience will be like. In theory, if team members and peers are more confident about the problems to be solved, then so too will be the respondent.

The mean average category scores for both groups are nearly identical, with a slightly higher deviation for the Post-Project Group. Looking closer, 85.6\% of the PreProject Group students answered 7 or higher, compared to $84.7 \%$ of the Post-Project Group students.

Two out of three questions here received slightly higher scores for the Pre-Project Group, with the exception being "If I am on the right team, we can accomplish anything," which showed a 0.109 unit increase for the Post-Project Group.

This is best described such that students actively engaged in a project that they have never seen rely more heavily on the experiences of those around them and those that have come before them, effectively weighting these Vicarious experiences higher than Mastery experience.

\subsection{Social Persuasions}

Here, student responses are based on social experiences beyond the classroom. Students were asked about friends and colleagues who were not helping them directly as team members, and also what those around them would think about them.

The mean average category scores for the Post-Project Group are higher than the Pre-Project Group, and the deviation is slightly lower. The percentage of students from the Post-Project Group who answered 7 or higher was $53.5 \%$, compared to the $51.2 \%$ from the Pre-Project Group. These numbers further diverge when we consider students who answered 6 or higher, where the PostProject Group had $69.4 \%$ compared to only $60.2 \%$ from the Pre-Project Group. The larger concentration at the top relates to higher self-efficacy from social influence in the Post-Project Group.

The largest difference was in the question "I often seek advice from friends (non-team members) when completing a design project" with a 0.746 higher score for the Post-Project Group. Having good friends who support and encourage a student will have a positive effect on self-efficacy.

\subsection{Physiological States}

In this category, students were asked about how interest in course material and marks might affect them. The relationship between students' interest in a course and their corresponding self-efficacy was studied.

The mean average for both groups in this category was very similar, but the deviation was slightly lower for the Post-Project Group. The Pre-Project Group showed a higher percentage of students answering 7 or higher, $64.9 \%$ compared to $60.4 \%$ for the Post-Project Group.

Per question, students from the Post-Project Group answered slightly higher relating to interest in the course, but the Pre-Project Group answered higher when asked about the effects of interim marks on perceived success in a course.

Students who had completed the project were more confident in their abilities to complete another, despite a proposed lack of interest in the course material, but students working on the project may have had more concern over the marks they would receive versus the marks they had received thus far in the course.

\subsection{Drive and Motivation}

The drive to succeed was directly measured in this section by a single question. The belief is that a student who has a strong desire to achieve success in the engineering profession will have more self-confidence and self-efficacy for engineering-related tasks.

Here, the mean averages were nearly identical for each group of students, but the deviation was slightly higher for the Pre-Project Group. The same holds for students answering 7 or higher, where the numbers were $86.6 \%$ for the Pre-Project Group and $85.4 \%$ for the Post-Project Group, with only a $1.2 \%$ swing between them. A similar trend can be seen at all response levels.

Drive to succeed may not have been directly affected by the design project, however only one question was used for assessment of Drive and motivation. Perhaps a more accurate result could be obtained with more questions.

\subsection{Generalized Self-Efficacy}

This measure was designed to use ten questions on a 1 to 4 Likert-scale, resulting in a score that varied from 10 to 40. Bandura [12] suggests that efficacy scales should have a higher deviation and recommends at least a 10point scale. The authors' survey employed an 11-point scale ranging from 0 to 10 . The GSE web site [14] includes data from over 18,000 respondents with a mean of 2.9 on their scale, equating to a mean of 6.333 on our 
modified scale. The suggestion is that no fewer than 7 questions be used for an accurate measure. Our survey used 8 of the available 10 .

The mean achieved by both groups was higher than the respondent data from the GSE web site. The overall mean of both groups was very close, with the Pre-Project Group results slightly higher in both mean and deviation. The percentage of students responding 7 or higher was $73.4 \%$ for the Post-Project Group over the $72.6 \%$ for the PreProject Group. The most common answer was 7 for both groups, with $23.7 \%$ from the Post-Project Group, compared with $21.5 \%$ from the Pre-Project Group.

The largest differences of the Post-Project Group over the Pre-Project Group in responses came from the questions "I am confident I could deal with unexpected events or project results" and "When confronted with a problem, I can usually think of a solution" which carried 0.347 and 0.331 unit response increases, respectively.

General Self-efficacy scale data, although interesting, may not be specific enough to offer insightful data. This data married with the specific engineering and design project-focused data provide a much more specific picture of self-efficacy as it relates to our work.

\subsection{Total Average From All Categories}

In this summary category, mean average was slightly higher for the Post-Project Group over the Pre-Project Group, with a lower deviation. Additionally, $71.6 \%$ of the Post-Project Group respondents answered 7 or higher in all categories over the $70.3 \%$ for the Pre-Project Group. This difference is greater when consideration is given to responses of 6 or higher, where the Post-Project Group had $81.3 \%$ compared with the Pre-Project Group with only $79.2 \%$, resulting in a $2.1 \%$ increase for the PostProject Group.

Since the General Self-efficacy scale data is somewhat non-specific, the average results from just the other categories was also considered. Here, the Post-Project Group responses had a mean average of 7.120 and a deviation of 1.010 over the Pre-Project Group with mean 6.987 and deviation of 1.245. The statistical significance value was $\rho=0.466$. Respondents from the Post-Project Group had $80.4 \%$ respond with an answer of 6 or more versus the Pre-Project Group respondents with only $76.9 \%$ answering that way, resulting in a $3.5 \%$ increase.

Based on either of these conditions, the overall selfefficacy was higher and more focused for the Post-Project Group, students who had already completed the project in the previous term.

\section{8 "I feel like an Engineer"}

One of the more interesting questions on the survey played directly to the level of involvement that students felt they had in the engineering community. This question stated "I feel like an Engineer" and offered the respondent the chance to agree or disagree on the same 11-point scale.

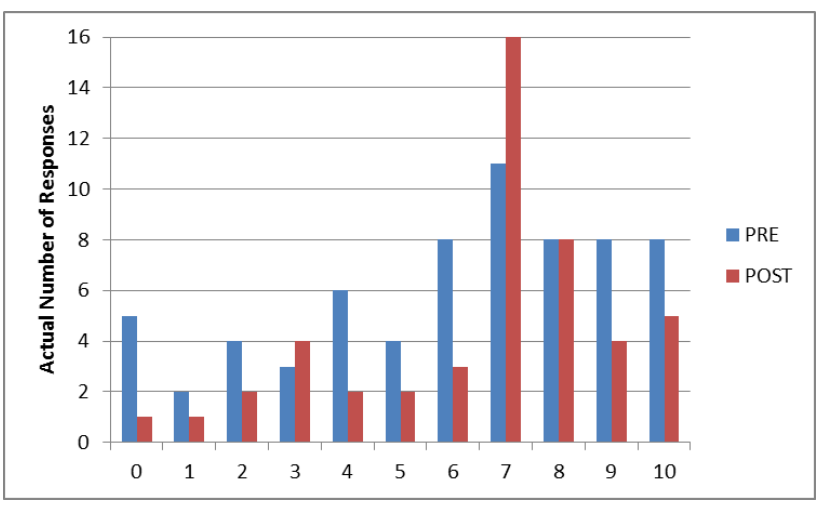

Figure 2: "I feel like an Engineer" responses

The mean average for the Post-Project Group was significantly higher than that of the Pre-Project Group, with a lower deviation. The most common answer given was 7 in both groups (evident in Fig. 2) obtained from $33.3 \%$ of the Post-Project Group population compared to only $16.4 \%$ of the Pre-Project Group. In addition, the Post-Project Group had $68.8 \%$ of students answer with 7 or higher compared with only 52.2\% from the Pre-Project Group. This indicates a much higher involvement of students who had completed the design project.

When the data between responses given for "Feel" and total mean average are correlated, the graphs shown in Figures 3 and 4 are obtained. Here it can be seen that feeling like an engineer (the red "steps" on the graphs) and self-efficacy (the blue lines) show a positive correlating trend in both groups, however the Post-Project Group convergence shows a greater correlation for students who have already completed the design project versus students who have not. Calculated correlation coefficients are 0.413 for the Pre-Project Group and 0.675 for the Post-Project Group, showing a greater correlation for students after the design project. Additionally, the Post-Project Group graph shows a much tighter formation around the trend line, where students not only show a higher self-efficacy, but are also more consistent in their responses.

\section{CONCLUSIONS}

Increases in self-efficacy and involvement were observed for the Post-Project Group, students who had completed the design project in the previous term over the Pre-Project Group, students who had not yet completed the design project. This was most notable in Mastery experiences and Involvement, where responses were higher for the Post-Project Group. The effects were less observable but still present in Social persuasions. No significant correlation could be found for Vicarious 
experiences, Physiological states, Drive and motivation or General Self-efficacy.

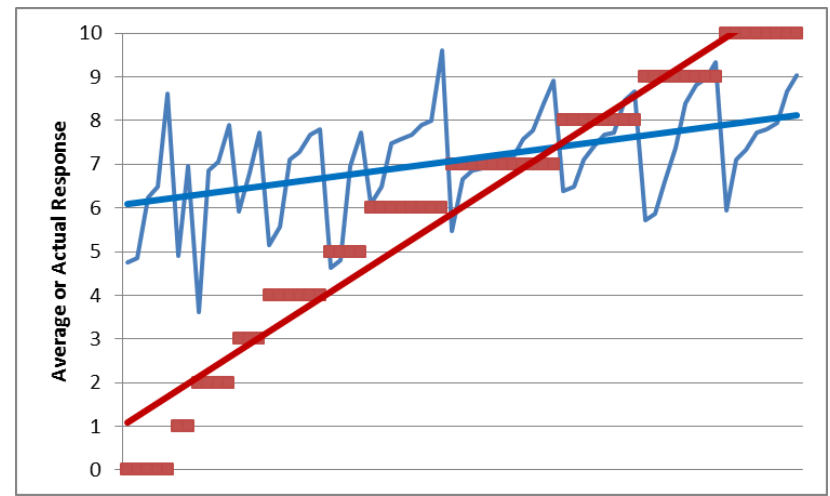

Figure 3: Pre-Project Group self-efficacy and involvement

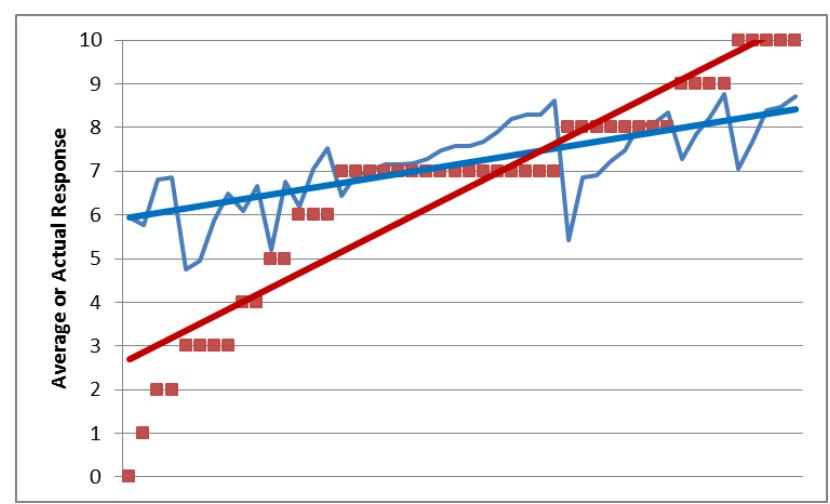

Figure 4: Post-Project Group self-efficacy and involvement

The main objectives were to find a relationship between self-efficacy, involvement and the design project, and those relationships were shown when considering the average of all categories. Additionally, the secondary objective was to show a correlation between self-efficacy and involvement (a sense of belonging to the engineering community) and that correlation was also present in both the Pre-Project Group and the Post-Project Group, with a stronger result from the Post-Project Group, students who had previously completed the design project.

The authors can say for certain that students feel more confident in their own engineering abilities, and feel a greater sense of community and involvement in the engineering community, when those abilities have been put to the test through design projects.

\section{Acknowledgements}

This paper and the research supporting it were made possible by funding from HEQCO, the Higher Education Quality Council of Ontario, support from Studica, and MapleSoft. The authors would also like to thank the Engineering 1 program at McMaster University for their support, and the first-year engineering student body at McMaster for their assistance in completing the survey.

\section{References}

[1] Deborah R. Compeau and Chrisopher A. Higgins, "Computer self-efficacy: Development of a measure and initial test," MIS Quarterly, vol. 19, iss. 2, pp. 189-211, June 1995.

[2] Jacquelynne S. Eccles and Allan Wigfield, "Motivational beliefs,values, and goals," Annual Review of Psychology, vol. 53, pp. 109-132, 2002.

[3] Victor J. Strecher, Brenda McEvoy DeVellis, Marshall H. Becker and Irwin M. Rosenstock, "The role of self-efficacy in achieving health behavior change," Health Education Quarterly, vol. 13, iss. 1, pp. 73-91, Spring 1986.

[4] Albert Bandura, Social Foundations of Thought and Action: A Social Cognitive Theory, Englewood Cliffs, N.J.: PrenticeHall, 1986, 544 pp.

[5] Mica A. Hutchinson, Deborah K. Follman, Melissa Sumpter, and George M. Bodner, "Factors Influencing the Self-Efficacy Beliefs of First-Year Engineering Students," Journal of Engineering Education, vol. 95, no. 1, pp. 39-47, January 2006. Available as of May 10, 2012 from http://jee.org/2006/january/6.pdf

[6] Todd D. Fantz, Thomas J. Siller, and Michael A. DeMiranda, "Pre-collegiate factors influencing the selfefficacy of engineering students," Journal of Engineering Education, vol. 100, no. 3, pp. 604-623, July 2011. Available as of May 10, 2012 from http://www.jee.org/2011/July/09.pdf

[7] Mica A. Hutchinson-Green, Deborah K. Follman, and George M. Bodner, "Providing a voice: Qualitative investigation of the impact of a first-year engineering experience on students' efficacy beliefs," Journal of Engineering Education, vol. 97, no. 2, pp. 177-190, April 2008. Available as of May 10, 2012 from http://www.jee.org/2008/april/8.pdf

[8] Senay Purzer, "The relationship between team discourse, self-efficacy, and individual achievement: A sequential mixed-methods study," Journal of Engineering Education, vol. 100, no. 4, pp. 655-679, October 2011. Available as of May 10, 2012 from http://www.jee.org/2011/October/03.pdf

[9] Petek Askar and David Davenport, “An investigation of factors related to self-efficacy for JAVA programming among engineering students," Turkish Online Journal of Educational Technology, vol. 8, iss. 1, pp. 26-32, 2009. Available as of May 10, 2012 from http://www.tojet.net/articles/v8i1/813.pdf

[10] Adam R. Carberry, Hee-Sun Lee, and Matthew W. Ohland, "Measuring engineering design self-efficacy," Journal of Engineering Education, vol. 99, no. 1, pp. 71-79, 
January 2010. Avaliable as of May 10, 2012 from http://www.jee.org/2010/january/8.pdf

[11] R. Schwarzer \& M. Jerusalem, "Generalized Self-Efficacy scale," in Measures in health psychology: A user's portfolio. Causal and control beliefs, J. Weinman, S. Wright, \& M. Johnston. Windsor, England: NFER-NELSON, 1995.

[12] Albert Bandura, "Guide for constructing self-efficacy scales," in Self-Efficacy Beliefs of Adolescents, Frank Pajares (ed.) and Tim Urdan (ed.). Information Age Publishing, Inc., 2006, 368 pp.

[13] Tak Wing Yiu, Sai On Cheung and Lai Ying Siu, "Application of Bandura's self-efficacy theory to examining the choice of tactics in construction dispute negotiation," Journal of Construction Engineering and Management $A S C E$, vol. 138, iss. 3, pp. 331-340, March 2012.

[14] Ralf Schwarzer. "General Self-Efficacy scale.” Internet: http://userpage.fu-berlin.de/health/selfscal.htm, May 30, 2011 [May 12, 2012].

\section{APPENDIX A: SURVEY QUESTIONS}

Please rate your response to the following statements on a scale from 0 to 10 , where 0 is "Strongly Disagree," 5 is "Don't Care" and 10 is "Strongly Agree."

1. Course material has prepared me for any sort of design project.

2. I have sufficient computer skills to conceptualize any design.

3. Weekly lab and tutorial assignments prepared me for the design project.

4. I am confident I can deal with any problems I encounter during a design project.
5. Knowing a project has been successfully completed by others makes me believe I am capable of completing the same project.

6. If I am on the right team, we can accomplish anything.

7. I will succeed even if one or more of my team members contributes nothing to a project.

8. Encouragement from my prof, TA or IAI is important to my ability to complete any project.

9. Online help (forums, email with TA/IAI) and office hours help prepare me for design challenges.

10. I often seek advice of friends (non-team members) when completing a design project.

11. I am confident I could complete a design project even if I had little interest in the course material.

12. I would be more likely to succeed in a course project if I already had a good mark in the course.

13. I want to succeed, so I will succeed.

14. I am able to cope and remain calm when facing project difficulties.

15. I am confident I could deal with unexpected events or project results.

16. I am confident I could personally succeed in any design project.

17. I am resourceful enough to handle unforeseen situations.

18. I can solve most problems by investing the necessary effort.

19. If someone opposes me, I can find the means to get what I want.

20. It is easy for me to stick to a project and accomplish my goals.

21. When confronted with a problem, I can usually think of a solution.

22. I feel like an Engineer. 